\title{
Experiências narrativas de professoras iniciantes: movimentos de socialização no cotidiano escolar ${ }^{1}$
}

\section{Narrative experiences of novice teachers: socialization movements in the daily life of the school

\author{
Experiencias narrativas de maestros principiantes: movimientos de socialización en la vida \\ diaria de la escuela
}

\author{
Inês Ferreira de Souza Bragança* \\ Joelson de Sousa Morais*
}

\section{Resumo}

O presente artigo tem como objetivo compreender os processos de socialização profissional de professoras iniciantes no cotidiano escolar, bem como refletir acerca da constituição das experiências nos primeiros anos da docência. O estudo foi desenvolvido na abordagem da pesquisaformação narrativa (auto)biográfica em educação, com os seguintes dispositivos metodológicos: imersão no cotidiano escolar, conversas, diário de pesquisa e narrativas escritas. Participaram da pesquisa três professoras iniciantes, pedagogas atuantes no $5^{\circ}$ ano do ensino fundamental em duas escolas da rede pública municipal de Caxias, MA. A fundamentação teórica pauta-se em: Josso (2010), Huberman (2000), Dubar (2012) e outros. Na compreensão e interpretação das narrativas, foi invocada a hermenêutica da narratividade e temporalidade em Paul Ricoeur (2010). O desenvolvimento do trabalho indica que os processos de socialização da experiência no cotidiano escolar pelas professoras iniciantes acontecem por meio de "ocupações" exercidas em contratos precários para desenvolvimento de atividades didáticas e pedagógicas com as turmas, no tempo do trabalho extraclasse das professoras efetivas por meio do "Terço da Jornada". Assim, as narrativas das professoras iniciantes apontam, ao mesmo tempo, para aprendizagens importantes na consolidação do campo profissional e, paradoxalmente, para aspectos de desprofissionalização do magistério das docentes em sua inserção no cotidiano institucional das escolas.

Palavras-chave: socialização profissional; professoras iniciantes; narrativas; cotidiano escolar; pesquisaformação.

Recebido em: 29/07/2020 - Aprovado em: 21/05/2021

http://dx.doi.org/10.5335/rep.v28i1.11455

Professora da Faculdade de Educação da Unicamp e docente colaboradora do Programa de Pós-Graduação em Educação Processos Formativos e Desigualdades Sociais da Faculdade de Formação de Professores da Universidade do Estado do Rio de Janeiro (FFP/Uerj). Realizou pós-doutorado pela PUCRS. Doutora em Ciências da Educação pela Universidade de Évora-Portugal. Mestre em Educação pela UFF. Coordena o Grupo Interinstitucional de Pesquisaformação Polifonia, vinculado ao Gepec (Unicamp) e ao Vozes da Educação (FFP/Uerj). Orcid: https://orcid.org/0000-0003-4782-1167. E-mail: inesbraganca@uol.com.br

* Doutorando em Educação pela Unicamp. Mestre em Educação pela Universidade Federal do Rio Grande do Norte (UFRN/2015). Pedagogo e pesquisador do Grupo de Estudos e Pesquisas em Educação Continuada (Gepec/Unicamp) e do Grupo Interinstitucional de Pesquisaformação Polifonia (Unicamp/Uerj). Professor Substituto da Universidade Federal do Maranhão (UFMA)/Campus Codó. Orcid: http://orcid.org/0000-0003-1893-1316. E-mail: joelsonmorais@hotmail.com 


\section{Abstract}

This article aims to understand the processes of professional socialization of beginning teachers in school daily life, as well as reflect on the constitution of experiences in the first years of teaching. The study was developed in the approach of research (narrative) (auto) biographical education, with the methodological devices: immersion in the school routine, conversations, research diary and written narratives. Three beginning teachers participated in the research, pedagogues working in the 5 th year of elementary school in two public schools in Caxias-MA. The theoretical basis is based on: Josso (2010), Huberman (2000), Dubar (2012) and others. In understanding and interpreting the narratives, the hermeneutics of narrativity and temporality was invoked in Paul Ricoeur (2010). The development of the work indicates that the processes of socialization of experience in the school routine by the beginning teachers happen through "occupations" exercised in precarious contracts for the development of didactic and pedagogical activities with the classes, during the time of the extra-class work of the effective teachers through of the "Terço da Jornada". Thus, the narratives of the beginning teachers point, at the same time, to important learning in the consolidation of the professional field and, paradoxically, to aspects of deprofessionalization of the teachers' teaching in their insertion in the institutional daily of the schools.

Keywords: professional socialization; beginning teachers; narratives; school life; research training.

\section{Resumen}

Este artículo tiene como objetivo comprender los procesos de socialización profesional de los docentes principiantes en la vida diaria escolar, así como reflexionar sobre la constitución de experiencias en los primeros años de docencia. El estudio se desarrolló en el enfoque de investigación (narrativa) (auto) educación biográfica, con los dispositivos metodológicos: inmersión en la rutina escolar, conversaciones, diario de investigación y narrativas escritas. En la investigación participaron tres maestros principiantes, pedagogos que trabajaban en el quinto año de la escuela primaria en dos escuelas públicas de Caxias, MA. La base teórica se basa en: Josso (2010), Huberman (2000), Dubar (2012) y otros. Para comprender e interpretar las narrativas, Paul Ricoeur (2010) invoca la hermenéutica de la narratividad y la temporalidad. El desarrollo del trabajo indica que los procesos de socialización de la experiencia en la rutina escolar por parte de los docentes principiantes suceden por "ocupaciones" ejercidas en precarios contratos para el desarrollo de actividades didácticas y pedagógicas con las clases, durante el tiempo de la extra-clase. trabajo de los profesores eficaces a través del "Terço da Jornada". Así, las narrativas de los docentes principiantes apuntan, al mismo tiempo, a aprendizajes importantes en la consolidación del campo profesional y, paradójicamente, a aspectos de desprofesionalización de la docencia de los docentes en su inserción en el cotidiano institucional de las escuelas.

Palabras clave: socialización profesional; maestros principiantes; narrativas; vida escolar; entrenamiento de investigación.

\section{Contextualizando a discussão}

Os primeiros anos da docência são marcados por uma infinidade de expectativas, anseios e incertezas na constituição da profissão e se configuram de modo fundamental para o desenvolvimento da carreira profissional. Alguns clássicos estudos desenvolvidos acerca do tema da socialização profissional, no contexto da sociologia das profissões, como é o caso dos realizados por Dubar (2012), mostram que os processos de socialização acontecem articulando educação, trabalho e carreira, possibilitando a construção das identidades dos sujeitos no contexto 
das instituições e em processos interativos coletivamente, caracterizando, assim, a legitimidade da profissão e da profissionalização.

O presente artigo tem como objetivos compreender os processos de socialização profissional de professoras ${ }^{2}$ iniciantes no cotidiano escolar, bem como refletir acerca da constituição das experiências nos primeiros anos da docência.

A perspectiva epistemológica e teórico-metodológica ${ }^{3}$ está pautada nos princípios da pesquisaformação narrativa (auto)biográfica em educação, articulados aos estudos da socialização profissional com os contributos de Josso (2010), Ricoeur (2010), Huberman (2000), Dubar (2012), Goodson (2019), entre outros. A pesquisaformação contou com a participação de três professoras iniciantes que atuam em duas escolas da rede pública municipal de ensino de Caxias, MA. Os dispositivos metodológicos tomados na produção do conhecimento científico foram: imersão no cotidiano escolar, conversas, narrativas escritas e diário de pesquisa.

A pesquisa foi desenvolvida entre os meses de fevereiro a março de 2020, antes do período de paralisação das atividades escolares, em decorrência da pandemia do Covid-19 do novo coronavírus, em momentos em que as docentes ainda estavam desenvolvendo a sua prática pedagógica no cotidiano escolar. Em Caxias, MA, as aulas foram paralisadas no dia 16 de março de 2020, por meio de decreto público municipal em consonância com o estadual, sobretudo, para as escolas, período este em que foram detectados os primeiros casos de Covid-19 na capital do estado do Maranhão, São Luís, então, não fomos mais às instituições, cessando, portanto, o contato presencial com as professoras iniciantes participantes da pesquisa, para evitarmos riscos que pudessem ser gerados pela pandemia. Participaram da pesquisa 03 (três) professoras iniciantes, formadas em licenciatura em Pedagogia e que se encontram atuando no $5^{\circ}$ ano do Ensino Fundamental em duas escolas da rede pública municipal de Caxias, MA.

Estamos compreendendo professoras iniciantes aquelas que se encontram no exercício da profissão docente em um recorte cronológico entre 01 a 03 anos, conforme indica Huberman (2000). Segundo este autor, nessa fase de início de carreira aludida no ciclo de vida profissional de professoras, estas apresentam, muitas vezes, duas latentes características que são evocadas narrativamente por elas nos estudos biográficos que realizou, quais sejam: a "sobrevivência" e a "descoberta". A primeira oscila muito em função do que acontece em seu cotidiano, seria um modo de ir construindo o perfil com o que lhe apresenta, (re)cria ou lhe é possível tecer, que poderá gerar impactos, alguns desânimos diante da realidade com que se defrontam e dos descaminhos ao longo de seus itinerários trilhados pelo "choque de 
realidade" que enfrentam. Enquanto que a segunda característica, a "descoberta", é o que move a primeira, no sentido de se configurar como saberes, práticas e situações que surgem de modo até inesperados, bem como acontecimentos e surpresas que as afetam de modo positivo, fazendo-as acreditarem na docência e a continuarem na profissão (HUBERMAN, 2000).

Uma das provocações reflexivas que mediatiza nossas ideias neste texto é conduzida pelo seguinte questionamento: como acontece a socialização de professoras iniciantes no cotidiano escolar, no contexto de um processo de desenvolvimento profissional?

Procedemos na compreensão e interpretação das narrativas das professoras iniciantes por meio da "hermenêutica da narratividade e temporalidade" em Ricoeur (2010), como uma forma tangível de atribuição de sentidos outros tecidos nos processos trilhados.

O artigo é composto de quatro partes, em que a primeira é esta "Contextualizando a discussão" apresenta um panorama inicial do estudo; a segunda traz os percursos metodológicos tematizados "Nas trilhas dos caminhos metodológicos: a centralidade da pesquisaformação"; a terceira seção elucida o tema "A socialização de professoras iniciantes nos caminhos da experiência profissional" com reflexões que situam como se deu a experiência das professoras iniciantes participantes do estudo em seus processos de socialização no cotidiano escolar; e a quarta e última parte traz as "Lições deixadas ou da incompletude de uma formação" com algumas reflexões trazidas pela pesquisa.

\section{Nas trilhas dos caminhos metodológicos: a centralidade da pesquisaformação}

A pesquisaformação é uma perspectiva da abordagem narrativa (auto)biográfica em educação que consiste em um processo de reflexividade potencializada pela formação e (auto)formação do pesquisador em diálogo com a realidade, os sujeitos que compartilham consigo a experiência de pesquisar e se formar ao mesmo tempo e em partilhar com os múltiplos acontecimentos que os acompanham nos itinerários percorridos.

Assim, na pesquisaformação não há uma separabilidade entre quem pesquisa e quem se forma, mas uma articulação profícua e simultânea desencadeada nos processos de aprendizagem, formação e constituição da experiência da pesquisa reciprocamente enquanto todos os envolvidos estão se transformando e tecendo uma 
consciência reflexiva dos percursos e itinerários que tecem ao longo da caminhada trilhada.

Segundo nos mostra Abrahão (2016, p. 31), a pesquisa-formação foi perspectivada no âmbito da corrente das histórias de vida em formação com Gaston Pineau, Marie Christine Josso e Pierre Dominicé nos inícios da década de 1980, no desenvolvimento de investigação com adultos e respectivos projetos de aprendizagem ${ }^{4}$. Com Pineau, na Universidade de Montreal, Canadá, e com Josso e Dominicé, na Universidade de Genebra, Suíça. António Nóvoa, partilhou com Domincé uma experiência de escrita (auto)biográfica que influenciou seus trabalhos que chegam ao Brasil nos anos 1990, trazendo significativa contribuição para nós.

$\mathrm{Na}$ acepção de Josso (2010), a pesquisa-formação implica uma tomada de consciência acerca do vivido, praticado e experienciado pelo sujeito durante os caminhos percorridos na construção da pesquisa e formação que se entretecem gerando possibilidades reflexivas, transformadoras no sujeito e permitindo a construção do conhecimento de si, dos contextos sócio-histórico-culturais, da profissionalização e formação. Segundo a autora, a abordagem "[...] demonstra a importância da atividade de integração de toda e qualquer aprendizagem num contexto, no caso presente, o da ecologia do pensamento do aprendente e o da sua atividade profissional" (JOSSO, 2010, p. 162).

Por isso, faz muito sentido a reflexão gerada por meio de uma elaboração narrativa em que o sujeito desenvolve durante o processo de pesquisa, o que também tem se dado em nossas práticas como pesquisadores, aos entrelaçar os múltiplos fios em que estamos a tecer com as professoras iniciantes no cotidiano escolar, tanto quanto isso acontece com elas, ao colocarmos em nossas conversas elementos disparadores para que possam narrar suas experiências iniciais de aprendizagem da docência em que estão se constituindo no campo profissional.

Temos desenvolvido a pesquisaformação em nossas produções e na pesquisa científica por uma escolha política, epistemológica e teórico-metodológica, além do fato de que esta perspectiva acaba tendo em vista uma potencialidade reflexiva e transformadora com que se configura na tomada de consciência em que o sujeito consegue se perceber, passando por transformações plausíveis, sedutoras e emancipatórias, que geram esse movimento de aprender, se formar e pesquisar, de forma complexa.

Nesse sentido, comungamos com as ideias de Motta e Bragança (2019, p. 1038) ao nos fazerem refletir que a pesquisaformação se inscreve como "[...] metodologias 
dialógicas entre o pesquisador e os sujeitos envolvidos, principalmente, por compreender que, nesse processo, a formação acontece em partilha, para ambos".

Desse modo, a imersão no cotidiano foi o primeiro fato que nos impulsionou a conhecer as professoras que possivelmente fariam parte da pesquisa, em conversas iniciais, nas quais foram escolhidas por apresentarem um perfil em que se encontravam nos primeiros anos como docentes, como também, foi o meio privilegiado em que tecemos nossas aprendizagens, formação e desenvolvimento da pesquisa, mediados por olhares, toques, sensações outras e processos de conversas, que foram compondo a produção do conhecimento científico.

Conversar com as professoras iniciantes, nos deu pistas para compreendermos suas vidas pessoais, profissionais e de organização e desenvolvimento do trabalho pedagógico, além das relações estabelecidas com as crianças, seus pares e demais agentes escolares, entre outras inúmeras possibilidades importantes correlacionadas aos seus saberes e fazeres dos processos de aprender e ensinar.

Ao primarmos pela conversa como dispositivo metodológico na pesquisa científica, estamos compreendendo que:

Não se trata, no bojo da conversa como metodologia de pesquisa, de categorizar as falas dos sujeitos interlocutores da ação investigativa, de inseri-las em quadros descritivos ou em conceitos-chave, recolher delas dados e analisa-los. Trata-se, antes, de pensar com elas, escutá-las, pensar a partir delas, com toda a imprevisibilidade, incomensurabilidade, inventividade e contingência que a pesquisa pode revelar (RIBEIRO; SOUZA; SAMPAIO, 2018, p. 169).

Assim, a conversa com as professoras iniciantes deu materialidade às compreensões e aos entendimentos que compartilhamos acerca do si e do nós, dos processos pedagógicos, da aprendizagem da profissão e dos movimentos de se constituir como docente no início de carreira, e das múltiplas outras questões que foram emergindo de uma forma menos categórica e fluída, já que conversar implica uma entrega, disponibilidade e troca recíprocas de saberes, experiências e conhecimentos que não estão dados, mas construídos na relação que estabelecemos com o outro, pensando bakhtinianamente (BAKHTIN, 2017).

No que concerne ao diário de pesquisa, foi o dispositivo metodológico que nos acompanhou no registro cotidiano das experiências que tivemos com as docentes, e de todos os acontecimentos que nos pareceram significativos e plausíveis serem registrados, para subsidiar nossas conversas em momentos posteriores, durante os encontros que juntos tivemos no cotidiano escolar. 
E foram nas narrativas que, evocadas pelas vozes das professoras em situações de sua prática pedagógica e das nossas conversas, que foram compondo o nosso inventário de pesquisa, para permitir a imbricação entre as diferentes experiências e registros que tivemos, permitindo a composição das ideias e tessituras do conhecimento científico, como o que culminou, por exemplo, nesse artigo.

Mergulhar no cotidiano escolar em um contexto de pesquisa científica, dá possibilidades outras de compreender e apreender uma realidade que se processa de uma pluralidade de formas, acontecimentos e sensações que somente estando imersos nas relações estabelecidas com os sujeitos com os quais dialogamos, participantes de nossas pesquisas, nos é possível construir. Desse movimento, emerge uma potencialidade rica de conhecimentos, saberes e experiências instituintes capazes de contribuir para a tessitura da emancipação social, ou como melhor nos faz pensar os estudiosos nos/dos/com os cotidianos a quem temos uma afinidade teórico-metodológica e epistemológica:

[...] cotidianamente, são criados conhecimentos e tecidas relações entre eles e seus sujeitos, relevantes não só para a vida cotidiana, mas para o desenvolvimento de novas práticas sociais de conhecimento e que podem contribuir com a tessitura cotidiana da emancipação social (OLIVEIRA, 2012, p. 53-54).

Nesse sentido, as professoras iniciantes são autoras e protagonistas de suas histórias, experiências e narrativas, as quais passamos, como pesquisadores, a elucidar essa dimensão potencial em nossas conversas fruto de suas narrações em processos de construção e aprendizagem profissional da docência, como fundamentais para a tessitura de seus saberes e conhecimentos de si, do que fazem, e das práticas pedagógicas enredadas em múltiplas outras questões relacionadas ao aprender e ensinar.

Diante desse contexto do desenvolvimento de uma pesquisaformação é plausível fazemos os seguintes questionamentos: Como chegamos até as professoras iniciantes? E como se deu a escolha para participarem do estudo?

Primeiramente, fomos à Secretaria Municipal de Educação, Ciências e Tecnologia de Caxias, MA (SEMECT), e conversamos com a Secretária Municipal de Educação, que nos recebeu, e com quem partilhamos o propósito da pesquisa que estávamos a desenvolver. Com base nesse primeiro contato, fomos direcionados ao setor de Recursos Humanos (RH), que fez um levantamento, trazendo uma lista com 08 (oito) professoras iniciantes, que estavam distribuídas em diferentes escolas da rede pública municipal. 
Fomos entrando em contato com algumas ao irmos pessoalmente para as escolas em que estavam listados os seus nomes, realizando uma primeira conversa, para que pudéssemos chegar à uma definição de quem poderia fazer parte da pesquisaformação. Nesse processo de conversa, identificamos que algumas professoras já tinham mais de três anos na docência, não sendo mais iniciantes, enquanto, nos levaram a conhecer outras que foram se adequando ao perfil da pesquisa, por sugestão de outras docentes que nos indicaram suas colegas. Após uma primeira conversa, definimos 03 (três) professoras localizadas em duas escolas, situadas em diferentes locais da cidade, pelo fato de estarem em um recorte cronológico que vai de 01 até 03 anos no exercício do magistério, se enquadrando, portanto, como professoras iniciantes, segundo Huberman (2000). São as que apresentamos neste trabalho e com as quais dialogamos na produção do conhecimento.

Por uma questão de ética na pesquisa científica não iremos revelar os nomes verdadeiros das participantes da pesquisa, e sim nomes fictícios, resguardando, portanto, suas identidades. Assim, serão designadas as docentes: Júlia, Liz e Fábia.

No início da pesquisa com as professoras iniciantes, explicitamos os princípios do estudo, e fomos dialogando com os esclarecimentos necessários relativos ao mesmo, elucidando os objetivos e as possíveis contribuições que pudesse trazer, e as professoras concordaram, bem como autorizaram que suas narrativas pudessem ser publicizadas em meios de divulgação científica, seja em revistas, livros ou eventos da área, entre outros. Agimos assim, pautados pela ética na pesquisa científica e com a responsabilidade com que concebemos a produção do conhecimento científico.

Quanto ao perfil das professoras iniciantes participantes da pesquisa, todas possuem formação inicial em Pedagogia, que foram cursadas em instituições da rede privada de ensino na cidade de Caxias, MA. Duas professoras, Júlia e Liz, realizaram o curso em uma mesma instituição, porém, em épocas diferentes, e a outra docente, Fábia estudou em outra instituição privada, em outro período diferente das outras duas professoras também.

E no que concerne à atuação profissional das professoras iniciantes que fizeram parte da pesquisa, estas se encontravam como docentes exercendo o ofício de professoras no $5^{\mathbf{0}}$ ano do Ensino Fundamental. Duas das professoras atuam em uma mesma escola no turno matutino (a Fábia e a Liz), e a outra professora (a Júlia) atua em outra escola localizada em outro bairro, e no turno matutino. Todas as 
três professoras participantes da pesquisaformação são docentes contratadas pela rede pública municipal de ensino e seus contratos ficam sob renovação a cada ano.

Para o processo de compreensão e interpretação das narrativas das professoras iniciantes nos fundamentamos na "hermenêutica da narratividade e temporalidade" de Paul Ricoeur (2010), como uma possibilidade tangível de produção de significados outros, de apreensão dos comportamentos e sentidos dos sujeitos que entrelaçam memória, experiência, tempo e narração.

No tocante à compreensão que consideramos ser uma dimensão potencial na pesquisa, reforçamos a dimensão de que faz Ricoeur (2010, p. 213) ao declarar que "[...] compreender a ação é reviver, reatualizar, repensar as intenções, as concepções e os sentimentos dos agentes".

Assim, ao entrelaçarmos a nossa imersão no cotidiano escolar, as conversas com as professoras iniciantes e os registros de narrativas escritas em nosso diário de pesquisa, fomos tecendo compreensões acerca do vivido e praticado, ampliando um leque de possibilidades que puderam se consolidar no processo de interpretação desse imbricamento de ações, permitindo, assim, a construção do conhecimento científico.

Daí o fato de que "[...] o momento de intepretação é aquele em que avaliamos, isto é, atribuímos sentido e valor" (RICOEUR, 2010, p. 196) às múltiplas experiências que fomos compondo juntos, mediados pelas ações que foram tramadas e tecidas cotidianamente nos percursos da pesquisaformação. A interpretação ganha, portanto, substancial legitimidade quando tecida nas relações entre quem pesquisa e os sujeitos participantes do estudo, em contextos que se consolidam na cultura institucional onde as professoras iniciantes estão tecendo as experiências, caso este que chegamos a perceber essa potencialidade.

Como se deu, então, metodologicamente a imbricação entre os registros das narrativas no cotidiano da pesquisaformação com os processos de compreensão e interpretação das mesmas na produção do conhecimento científico?

Através de nossa imersão no cotidiano da escola, na participação com as professoras em sala de aula e em outros espaços educativos da instituição no tocante às suas práticas, e ao mesmo tempo durante as conversas em que íamos, enquanto pesquisadores, registrando por escrito em nosso diário o que ia surgindo desse processo de conversação, além de outros ditos e não ditos que se implicavam em gestos, comportamentos, aspectos corporais e sensitivos que revelavam e que percebíamos das professoras iniciantes e dos múltiplos atravessamentos outros, no plano de uma educação das sensibilidades no sentido benjaminiano (BENJAMIN, 
2012), como uma racionalidade sensível na produção do conhecimento científico como também faz alusão Bragança (2012), que se deu, de modo assimétrico, não controlado e nem circunscrito a uma temporalidade estabelecida, como campo de possibilidades que emergiam das interações tecidas entre nós.

Assim, o que registrávamos no plano da escrita em nosso diário de pesquisa, foram aos poucos compondo uma narrativa, em que não apenas transcrevíamos o que nos diziam as professoras iniciantes durante nossas conversas, mas, fizemos uma construção mesmo narrativa mediada por uma reconstrução a posteriori e de um modo mais elaborado, a partir do que dialogávamos com elas, em que as professoras iniciantes passavam a entender e saber o que tínhamos escrito nos encontros, e nos diziam outros tantos acontecimentos relacionados ao que líamos do nosso diário fruto de sua experiência que registramos por escrito, passando a ser, portanto, um processo de reconstrução da narrativa, trazendo, assim, uma compreensão e interpretação coletiva da experiência narrativa que juntos fomos produzindo ao longo da pesquisaformação.

\section{A socialização de professoras iniciantes na construção da experiência profissional}

A ideia que estamos concebendo como socialização profissional relaciona-se com um processo de inserção na cultura institucional pelo sujeito levando atitudes, valores, modos de racionalizar e organizar suas dinâmicas pessoais e profissionais, constituindo outras tantas possibilidades de aprendizagem com os outros nas mediações estabelecidas que possam surgir no cotidiano do trabalho. Ao pensarmos por esse prisma, partimos do princípio que "[...] a socialização profissional é, portanto, esse processo muito geral que conecta permanentemente situações e percursos, tarefas a realizar e perspectivas a seguir, relações com outros e consigo (self), concebido como um processo em construção permanente" (DUBAR, 2012, p. 358).

Para tecermos maiores aprofundamentos nesta parte do texto, urge um questionamento fundamental: como se socializam as professoras iniciantes participantes da pesquisa no contexto de seu desenvolvimento profissional no cotidiano das escolas? E quais experiências tecidas na vida das docentes? Como encararam os acontecimentos propiciados nos primeiros anos da profissão de professora iniciante?

Antes de refletirmos sobre essas questões, trazendo as narrativas das professoras iniciantes, e como uma forma de compreendermos o que nos revelaram estas, 
com base em nossas conversas com algumas coordenadoras pedagógicas que atuam dentro da Secretaria de Educação, e por meio do nosso diálogo com a secretária de educação, ressaltamos que no município em que atuam junto às escolas públicas da rede municipal da SEMECT, não possui propriamente uma política específica ou programa de acompanhamento e orientação destinado a professores e professoras que iniciam o seu trabalho no cotidiano das escolas. Sobretudo, para docentes iniciantes, que nunca desenvolveram o seu trabalho como professores/as, ou aqueles/ as que ainda não tiveram a experiência de ser professor/a.

De acordo com as conversas que tivemos com as professoras iniciantes, em compartilhamento de suas experiências narrativas do início da profissão docente, as aprendizagens da profissão e os processos de socialização profissional, portanto, acontecem em experiências que vão sendo descortinadas pelas docentes, em função do contato com a cultura escolar e do que encontram no cotidiano da instituição, das relações estabelecidas com outras professoras que já tiveram alguma experiência ou que já se encontram na carreira do magistério, bem como através da (re) criação de dispositivos didáticos-pedagógicos que julgam ser necessários criarem e desenvolverem com seus alunos, além de aprendizagens que passam a ter com seus filhos, do que trazem da escola para casa, servindo como subsídios para empreenderem no seu trabalho com seus alunos na escola onde trabalham.

No que se refere ao conceito de experiência estamos concebendo-a a partir da perspectiva de Benjamin (2012) como um processo de afetação que se configura na vida do sujeito, passando a gerar implicações transformadoras e significativas que marcam os seus percursos trilhados e lhe dão consciência do acontecimento que passa a ser evocado em suas memórias em diferentes momentos de sua existência.

Na perspectiva de Larrosa (2011), estamos compreendendo a experiência como um acontecimento que nos passa e que respondemos com a afetação e implicação que é gerada desse movimento entre o mundo externo e o interno, capaz de produzir uma reflexão, transformação e mudança podendo nos acompanhar em diferentes espaços-tempos da vida, formação e existência. A experiência, é, portanto, "[...] um movimento de ida e volta [...] que vai ao encontro com isso que passa, ao encontro do acontecimento" (LARROSA, 2011, p. 6).

Buscamos, nas linhas que se seguem, trazer os diferentes acontecimentos que foram se descortinando narrativamente na experiência dos primeiros anos de professoras iniciantes no cotidiano do desenvolvimento profissional, a partir do que enunciaram as participantes da pesquisa durante os encontros que tivemos com 
elas nas escolas, caracterizando-se, assim, como processos de socialização profíssional na carreira docente.

A professora Júlia iniciou suas atividades profissionais na escola no segundo semestre do ano de 2017, e começou através do "Terço da Jornada" . Segundo nos narrou a professora Júlia:

O Terço da Jornada é um programa em que desenvolvemos atividades com turmas do $1^{\circ}$ ao $5^{\circ}$ ano do Ensino Fundamental. É destinado a professores temporários com várias disciplinas em diferentes tempos, horários e escolas, visando com que estes possam "cobrir" o tempo dos professores efetivos, que possuem um dia disponível para sua formação e estudo, e que os outros professores acabam ocupando esse outro tempo (Narrativa da profa. Júlia, 19/02/20).

Como podemos perceber, a professora Júlia compreende os princípios e contradições do exercício da docência no "Terço da Jornada", mas encontrou nesta oportunidade de trabalho a possibilidade de ingressar como docente em uma escola da rede pública de ensino. A organização da jornada de trabalho das professoras participantes da pesquisa vem como consequência da Lei $\mathrm{n}^{\circ} 11.738$, que instituiu o Piso Salarial Profissional Nacional para os profissionais do magistério público da educação básica (PSPN), em 2008.

Tendo como referência uma jornada de quarenta horas semanais, a Lei do PSPN estabelece um vencimento base ajustado anualmente, bem como o limite máximo de dois terços do tempo para efetivo trabalho de interação com os estudantes e um terço do tempo de trabalho sem estudantes, chamado extraclasse. Dessa forma, tendo como referência uma jornada de 40h semanais, 26 horas devem ser destinadas ao efetivo trabalho com os estudantes e 14 horas às atividades extraclasse (BRAGANÇA; PEREZ, 2016, p. 1167).

A Lei do Piso, como ficou conhecida, afirma-se com importante conquista dos profissionais da educação, consistindo na dedicação de um terço da jornada de trabalho ao estudo, planejamento e avaliação. Trata-se de incentivo e valorização profissional, implicando em melhores condições de trabalho. O cumprimento da referida lei consiste em um desdobramento do que já havia sido preconizado na Lei de Diretrizes e Bases da Educação Nacional (LDB), Lei nº 9.394/1996 (BRASIL, 1996), sobretudo no artigo 67, que trata da valorização dos profissionais da educação.

O desafio posto é o cumprimento desse piso salarial dos professores no que diz respeito às administrações públicas espalhadas pelo Brasil, no sentido de assegurar o terço de horas-atividade para as docentes no contexto de trabalho na educação básica. E vale ainda ressaltar que esta lei é garantida para os profissionais da educação básica que são concursados na rede pública, o que não contempla professores e professoras que são contratados em regime temporário, como no caso das professoras iniciantes que fizeram parte desta pesquisaformação. São múlti- 
plas as contradições na operacionalização em muitos municípios para atender a legislação, em que fazem a contratação de professores temporários que "cobrem" os horários extraclasse dos docentes efetivos, desenvolvendo atividades pedagógicas com as turmas. No município de Caxias-Maranhão, a referida atuação profissional é denominada informalmente pelas professoras como "Terço da Jornada".

Assim como as participantes da pesquisaformação, observamos que muitos professores iniciantes na profissão começam a atuação na docência por estar via de trabalho precarizado e o que desenvolvem, como fazem e as múltiplas características que empreendem em seu trabalho, trazem implicações avaliativas que podem contribuir para conseguirem "conquistar uma vaga" na escola e trabalhar como docentes em um regime de contratação, ainda que também de forma precária, com atuação profissional em uma turma, consistindo em uma melhoria nas condições de trabalho.

O "Terço da Jornada" tem representado um lócus de aprendizagem inicial do ser professora com diferentes configurações, em que muitas passam a se inserir na cultura escolar, a conhecer as dinâmicas pelas quais funcionam, e a ter a oportunidade de "mostrar o seu trabalho" para continuar no cargo ou passar de um status para o outro.

Essa constituição dos espaços de trabalho na formação e aprendizagem da profissão durante os processos de socialização das professoras iniciantes no cotidiano escolar, em termos do que desenvolvem no "Terço da Jornada", acreditamos que se relaciona mais como uma "ocupação" do que uma "profissão" nos termos de Dubar (2012), já que as docentes revelaram, em nossas conversas, que desenvolviam diferentes tipos de atividades focando as áreas do conhecimento que a elas era designadas, em várias turmas e em duas ou mais escolas. O que, com o passar do tempo, somente veio a conquistar uma vaga de trabalho, como professora contratada de somente uma turma em uma escola, passando a alçar o status, de fato de professora, como ficou bem marcado em suas narrativas essa transição.

Ainda segundo a professora Júlia, acerca dessa experiência, revelou-nos que o fato de atuar no "Terço da Jornada":

[...] não permitia com que a gente criasse vínculo com a turma, com os alunos, o que isso dificultava de desenvolver um trabalho mais minucioso e específico no que se refere às dificuldades de aprendizagem e relacionadas ao acompanhamento do comportamento das crianças, já que não dava para conhecer o perfil dos mesmos (Narrativa da professora Júlia, 19/02/20).

Diante do exposto, podemos notar que as atividades desenvolvidas pela docente, indicam uma forma de buscar iniciar-se na profissão, ou mesmo conquistar um 
espaço e legitimidade que venha a se consolidar. Outro aspecto se torna fundamental trazer, ao que Estrela (2010, p. 46) vai designar pela "dimensão pedagógica dos sentimentos e emoções dos professores e professoras", quando chegamos a perceber as questões implícitas de afetação que a professora demonstrou ao narrar essa experiência mencionada anteriormente. Transpareceu-nos que ela estava no plano do desejo e da expectativa em querer uma turma que ficasse sob sua responsabilidade, em que pudesse criar vínculos e se envolver afetuosamente com as crianças no processo de ensino e aprendizagem, e poder acompanhá-las durante todo o ano letivo, para mediar os processos educativos e pedagógicos na caminhada.

A professora Julia continuou desenvolvendo o seu trabalho na mesma escola em que se encontra atuando hoje, desde 2017, e foi essa experiência no desenvolvimento de atividades em sua prática pedagógica, que a fez "conquistar" a tão sonhada vaga como professora, no ano seguinte em 2018, em uma turma somente sua, mudando o status de "ocupação". Percebemos que para ela, como para outras também, a mudança para atuação em uma turma traz maior segurança no campo profissional, embora, sabendo que sua permanência no cargo, continua correlacionada à sua atuação, e que, portanto, sua competência profissional estava em processo de consolidação, bem como sob avaliação da equipe gestora da escola e dos resultados da aprendizagem que os alunos pudessem desenvolver e obter pelo que fazia.

$\mathrm{O}$ estar presente e inserido no cotidiano como pesquisadores, mas também como professores e vivendo um processo de formação com as docentes, nos traz outros tantos olhares e construção de percepções, entendimentos e compreensões acerca do vivido e praticado. São nesses momentos que extrapolamos a dimensão prescritiva e da racionalidade técnica tão presentes no âmbito da educação. Por isso, nos foi possível apreender outras tantas significações que somente as palavras e as narrativas não nos deram conta: o viver e experienciar a sala de aula, o contato com as crianças e as conversas com as professoras dentro do seu âmbito de trabalho, e nos diferentes espaços-tempos da cultura escolar e da interação com os múltiplos sujeitos que nela habitavam ou que visitavam/participavam reafirma a ultrapassagem de um trabalho de pesquisa para o sentido de pesquisaformação.

Nesse aspecto, acreditamos ter praticado uma "racionalidade sensível, incorporando a vida dos sujeitos, em toda sua complexidade existencial, como componente fundamental do processo formativo" (BRAGANÇA, 2012, p. 28). O que também nos remete a pensar no que esta mesma autora ressalta quanto a "experiências instituintes de formação", que acreditamos ser como aquelas tecidas em dinâmicas 
singulares-plurais que os sujeitos possam revelar, e que impulsionam uma potencialidade transformadora e emancipatória na vida, formação e profissão.

Olhamos, portanto, a socialização profissional no contexto da educação como uma perspectiva singular e que se constitui diferentemente de uma realidade para outra. É um vir a ser que vai imprimindo um modo outro de consolidação em um espaço de trabalho em que professores e professoras iniciantes ou experientes enfrentam subjetivamente e a partir das condições materiais de existência, trabalho e profissão.

Assim, mesmo que "[...] a questão da profissionalização é assim redefinida pelos interacionistas como um processo geral” (DUBAR, 2012, p. 356), há uma natureza de singularidade pela qual o sujeito constrói nas mediações da cultura institucional, com os sujeitos com os quais estabelece relações e com os múltiplos atravessamentos que vão sendo tecidos ao longo do aprender, ensinar, organizar o trabalho pedagógico e dos enfrentamentos pelas lógicas hegemônicas e contra hegemônicas que se tecem à sua volta: das diretrizes educacionais preconizadas no seu trabalho, do currículo escolar, da avaliação, do planejamento e de múltiplas outras questões que emergem nesse processo de socialização profissional da profissão de professora.

Já em relação à professora Liz, esta iniciou como professora também com atividades desenvolvidas no "Terço da Jornada", no ano de 2017, mas em duas escolas e com cinco turmas, ministrando diferentes disciplinas. Fazendo uma reflexão acerca dessa experiência, a professora relatou que:

Uma professora do "Terço da Jornada" trabalha muito mais do que a que fica numa turma só. $\mathrm{Na}$ época eu trabalhava em duas escolas e com cinco turmas, em diferentes horários, e na minha época eram as disciplinas de Artes, Educação Física e Religião, esse ano é História e Geografia (Narrativa da professora Liz, 04/03/2020).

A experiência desenvolvida pela profa. Liz demonstra os movimentos de se constituir professora em um contexto multifacetado da didática, de enfrentar muitas turmas e se deslocar de um lugar para o outro, em se tratando das atividades desenvolvidas em diferentes escolas, como uma das propostas preconizadas por essa realidade e que, mesmo se tratando de ser mutável de um tempo para o outro, a docente ainda carrega memórias que foram importantes no processo de se tornar professora e passar de uma fase à outra da profissão, ou seja, de ser professora no "Terço da Jornada", e agora estar compromissada apenas com uma turma e em uma escola. Fica explícito que é exatamente isso que a professora queria, já que 
consegue desenvolver um trabalho e acompanhar o andamento das crianças em todos os percursos formativos da experiência educativa.

É no processo de narrar que as docentes conseguem se enxergar e tomar consciência de sua prática e das relações estabelecidas com a cultura escolar, as crianças, seus pares e os múltiplos atravessamentos e deslocamentos gerados no movimento entre aprender, educar e ensinar.

Podemos dizer que a professora Liz teve uma experiência, a qual foi fundante para resgatar no plano da memória o que aprendeu com as atividades que desenvolveu no "Terço da Jornada", situando o passado no presente pela sua narração.

Tal perspectiva nos remete à reflexão da temporalidade da narrativa com que empreende Ricoeur (2010), em Tempo e narrativa, quando a professora iniciante situa o que viveu em sua experiência do passado no início de se constituir como professora, refletindo no presente esses acontecimentos que foram marcantes para ela. O que Ricoeur (2010) vai refletir acerca do tríplice presente, em Santo Agostinho, de que a narrativa é produzida em: um presente do passado, um presente do futuro e um presente do presente.

Nesse sentido, a professora iniciante Liz retratou o que desenvolveu, como era o seu trabalho baseado na realidade da época, e fez uma comparação no momento atual, com reflexões de como se dá o ser professora em relação ao tempo que atuou no "Terço da Jornada", com o que está desenvolvendo agora. Acreditamos ser uma forma de perceber as nuances e diferenças que envolvem a organização e desenvolvimento do trabalho pedagógico, já que no momento se encontra como professora em uma turma só, questão essa desejada por ela, e que foi "conquistada" fruto do seu trabalho, da sua didática e do que desenvolveu para chegar ao status que se encontra atualmente: professora contratada de uma turma somente em uma escola.

A relação com os demais pares de professores da escola e de outras, e suas relações com a equipe de gestão, também foi outro fator que trouxe elementos de referência para que a professora pudesse fazer uma reflexão nos momentos iniciais que enfrentou nas escolas no aprender a ser professora, como percebemos essa dimensão durante nossas conversas, e que vez por outra emergiam em suas narrativas esse aprender com o outro.

Acerca das características que se manifestam no início da carreira docente no processo de socialização profissional, parece-nos tangível declarar que “[...] neste primeiro ano, os professores são principiantes, e, em muitos casos, no segundo e terceiro anos podem estar ainda a lutar para estabelecer a sua própria identidade pessoal e profissional" (MARCELO GARCIA, 1999, p. 113). 
Aspecto esse que percebemos se fazer presente tanto no que se refere à vida profissional da professora Liz, que aludiu também isso em suas narrativas, como se relaciona com as outras duas professoras participantes desta pesquisaformação. $\mathrm{O}$ que fazem e mobilizam de saberes e fazeres contribuem enormemente para a construção do perfil, didática e modo de ser professora iniciante e que acompanhará as mesmas ao longo do processo de socialização no campo profissional, sendo construído e reconstruído na trajetória docente, em um processo sempre aberto ao longo da vida.

Outro aspecto pertinente a ser compreendido diz respeito às relações coletivas constitutivas do ser e se transformar nesse entrecruzamento. Isso nos lembra Bakhtin (2017) acerca dos processos relacionais em que o sujeito produz com o outro, possibilitando a constituição de si e dos modos, em que, coletivamente se transformam, reforçando o que o autor chama de relações de alteridade que vão imprimindo um caráter axiológico de que resulta desse processo interativo, de engajamento e produtor de uma multiplicidade de significações. O sujeito passa não apenas a se transformar, mas a tomar consciência em reflexões que tece desse passar de uma condição para a outra mediada pelas relações humanas coletivas.

No que se refere a outra professora iniciante, Fábia iniciou seu trabalho como docente na escola em maio do ano de 2018 também no "Terço da Jornada", em cada dia numa sala em turmas diferentes, e que se prolongou com as atividades ao longo do ano de 2019, passando a assumir uma turma só sua, já como professora contratada neste ano de 2020, no $5^{\mathrm{o}}$ ano do ensino fundamental.

Segundo narra Fábia, em uma conversa que tivemos, acerca de suas experiências iniciais de inserção profisssional na docência, ser professora no "Terço da Jornada":

É um desafio constante. A gente tem que se reinventar e se permitir a novas aprendizagens. A maior dificuldade é vencer as barreiras da questão social dos alunos, pois muitos não tem condições tanto financeiras para adquirir os materiais escolares, quanto do acompanhamento familiar dos pais no processo de ensino e aprendizagem (Narrativa da professora Fábia, 03/03/20).

Tal narrativa nos leva a refletir acerca da complexidade que emana dos processos pedagógicos, educativos, e, sobretudo, humanos e emocionais que atravessam a docente, e que influenciam nos modos de constituição de suas identidades profissionais, nesse início de carreira, quando de sua socialização na cultura escolar.

Algumas das narrativas que foram surgindo em nossas conversas, foram sendo reveladas espontaneamente pela docente, em momentos em que percebemos uma 
necessidade de compartilhar com um outro, o que por vezes acreditamos ter sido uma necessidade de fazer isso com outras professoras na escola, embora, estivéssemos com ela em outra condição: de pesquisadores-formadores, mas também constantes aprendizes do ser professor, no contexto da escola pública básica, nesse caso.

A professora Fábia, demonstrou narrativamente suas dificuldades em alguns momentos que começou a rememorar de sua socialização profissional no cotidiano da escola. Um de seus discursos pontuou que:

Olha não é fácil. Eles [alunos] leem de uma forma e escrevem de outro jeito, do jeito que eles acham que sabem. Tem horas que a garganta dói de tanto eu tá explicando, e as pernas doem, andando na sala de aula pra poder ajudar a eles, porque no final do ano eu preciso apresentar resultados (Narrativa da professora Fábia, 03/03/20).

As dificuldades, portanto, reveladas pela professora Fábia, são algumas das muitas em que permeiam o trabalho da professora em início de carreira, que passa a se esforçar e aprender na própria prática como é ser professora, com a realidade que possui, e os múltiplos acontecimentos que perpassam o seu campo profissional e que podem reverberar emocionalmente em como a docente se sente.

Além do mais, como a professora ainda está nos movimentos iniciais de seu processo identitário profissional e de socialização, isso pode se configurar como momentos de oscilação entre os impactos que enfrenta cotidianamente em um contexto em que não estava acostumada a enfrentar, em se tratando da escola pública, como nos revelou narrativamente a professora em outras conversas ${ }^{6}$, e que, os esforços empreendidos para contribuir no processo de ensino e aprendizagem, é uma das questões que trazem muitas reflexões e acompanham-na em afirmar-se na profissão de professora.

Conforme revelou em outra narrativa, Fábia disse-nos que sofreu um "choque" quando passou de uma transição como professora da Educação Infantil que só tinha 11 alunos e entrou nessa escola da rede pública do Ensino Fundamental com uma turma de 35 alunos. Essa transição entre ser professora do "Terço da Jornada" mexeu muito com a docente, que narrou:

Ano passado foi muito difícil, pensei até em desistir. A turma que eu peguei eram 15 alunos no "Terço da Jornada", porque eram repetentes. Então, tinha dias que eu chorava em casa e chorava, porque eu parava e pensava na situação deles [alunos] de não querer nada com a vida (Narrativa da professora Fábia, 20/02/2020).

Os múltiplos acontecimentos que surgem nos primeiros anos da profissão docente, no processo de socialização profissional, parecem ser importantes para a continuidade ou o abandono da profissão. Tanto que, pela narrativa da professora 
Fábia, suas primeiras experiências na docência reverberaram em sua subjetividade, desencadeando emoções, gerando outros tantos estados de ser e estar, levando ao questionamento quanto à continuidade ou ao abandono do magistério.

Em uma pesquisa longitudinal desenvolvida por Goodson (2019) e apresentada no livro Currículo, narrativa pessoal e futuro social, entre as quais envolveu professoras iniciantes nos dois primeiros anos da docência, o autor identificou que "[...] acompanhando-os pelos primeiros dois anos de docência, vimos esses professores se esforçarem para definir seu(s) novo(s) papel(papéis) e contextos e para se perceberem como professores no cenário da faculdade comunitária" (GOODSON, 2019, p. 146).

As professoras iniciantes participantes desta pesquisa, não se mostraram indiferentes a essa perspectiva, já que revelaram preocupação em constituir a sua profissionalidade e um perfil de ser professora ainda no início da carreira docente. $\mathrm{O}$ que também foi reforçado por suas narrativas e durante os encontros que com elas tivemos no cotidiano escolar.

A narrativa no processo de pesquisaformação, parece-nos ser um dispositivo potencial de formação, reflexão e construção de saberes e conhecimentos que vão configurando o ser e aprender a ser professora iniciante mediada pelas experiências de narrar o que lhes acontecem, e como encaram esse acontecimento na vida que dá significação e sentido que se revela por meio de contar o que fez, o que pensa e o que está refletindo. Tal como conseguimos perceber durante a escrita narrativa que fomos registrando em nosso diário, do que nos narravam as professoras iniciantes durante as conversas no cotidiano escolar. Cabe-nos salientar uma citação elucidativa desta questão, qual seja, de que:

As narrativas escritas nos oferecem a oportunidade de trabalhar sobre essa questão das experiências fundadoras que, em boa parte, são constituídas pela narração de microssituações (designadas, às vezes, por episódios significativos) que pressupomos não estar aí por acaso. O trabalho sobre esses microacontecimentos da vida permite destacar as componentes de uma vivência que se transformaram em experiência (JOSSO, 2010, p. 214).

Portanto, os acontecimentos que se processaram na vida e na profissão das professoras iniciantes ao passarem em suas inserções profissionais no processo de socialização da profissão constituíram de uma singularidade da qual foi tecida à luz das experiências do se fazer e viver a profissão, do estar em contato com uma realidade e enfrentar os percalços e as conquistas da consolidação do status profissional, bem como dos aprendizados e das marcas que esses movimentos conseguiram lhes trazer como fundantes para se tornarem professoras, mesmo em 
situações e modos que não tenham sido as que esperavam ou que passaram a se consolidar em conquistas do que queriam.

Do mesmo modo, não podemos nos furtar de deixar claro que os processos de socialização profissional com que as professoras iniciantes passaram ao se inserirem no contexto de trabalho, foi constituído de um teor de desvalorização profissional, pois passam a ser vistas mais como uma ocupação de atividades no "Terço da Jornada" - no lugar daquela professora que está gozando desse direito legal que lhe foi assegurado - enquanto as professoras iniciantes, tiveram que desenvolver o seu trabalho às custas do que lhes foi possível ter de oportunidades para, então, “conquistar" uma vaga de emprego como professoras contratas, o que aponta para um outro status de mobilidade profissional com um pouco mais de durabilidade e prestígio. A esse respeito, é válido reforçar que:

É nesse quadro de trabalho escolar, permeado por processos de desqualificação e de intensificação do trabalho, que o professorado em início de carreira se insere, tendo que enfrentar diferentes desafios inerentes ao exercício da profissão e, ao mesmo tempo, sendo desafiado e impulsionado a agir dentro das regras, como as preconizadas pelas políticas regulatórias (ILHA; HYPOLITO, 2014, p. 107).

De um lado, eis o aprender uma profissão com a realidade que se apresenta e com o que lhes foi dado de oportunidades na construção de um campo profissional, de outro, a desvalorização e condições precárias de ser e aprender a ser docente, com cargas horárias várias, muitas turmas e um constante movimentar-se entre as muitas disciplinas, vários alunos e escolas. E, assim, são os processos de socialização de professoras iniciantes com que nesta pesquisaformação nos foi possível perceber, numa dada realidade, em um dado tempo e em um contexto de transformações sociais, econômicas, políticas e culturais do momento em que vivemos e estamos. E que vai diferenciando-se de um tempo e sociedade para o outra.

\section{Lições deixadas ou da incompletude de uma formação}

Ao desenvolvermos a pesquisaformação, entremeada com as articulações discursivas expressas nas narrativas e das experiências das professoras iniciantes, chegamos às seguintes provocações reflexivas: como se socializam as professoras iniciantes? Que experiências lhe pareceram significativas e como as revelam nos primeiros anos da docência?

A sensação de "conquista" foi a que nos transpareceu bem visível durante nossas conversas e no modo como revelaram as professoras iniciantes em relação às 
diferentes aprendizagens que conseguiram ter e construir, além da inserção no cotidiano profissional nas escolas que foram determinantes para conseguiram estar como professoras no momento atual.

Uma das questões que na realização deste estudo ficou latente para nós: o modo como as professoras iniciantes foram se socializando caracterizou-se em um contexto de desprofissionalização do ofício docente, já que tiveram que "passar" primeiramente pela experiência de serem professoras do "Terço da Jornada", para poder mostrar o seu trabalho, tendo a possibilidade de serem contratadas em um regime temporário, sujeito a renovação contratual a cada ano, também de caráter precário.

Pelas narrativas das professoras iniciantes participantes da pesquisaformação, foi possível percebermos a ideia de "conquista" do campo profissional, mediada pelos processos de socialização no cotidiano escolar por meio das atividades pedagógicas e didáticas no "Terço da Jornada" em diferentes turmas e escolas.

As experiências pedagógicas e de aprendizagem da profissão docente mostraram-se através das conversas que tivemos com as professoras iniciantes e do acompanhamento da pesquisaformação em que mergulhamos no cotidiano escolar, um modo específico e singular de socialização profissional no contexto educacional, o que certamente poderá se diferenciar de outros modos de socialização no campo da educação, e por outras professoras iniciantes ou experientes.

Além do mais, os acontecimentos pelos quais foram tecidos nas experiências de socialização profissional nas escolas pelas docentes iniciantes, demarca um tempo histórico, um entendimento de políticas, educação, cultura e sociedade pelas quais estão se consolidando no momento atual, que outrora tinha outras dimensões e experiências, e que, certamente se diferenciarão futuramente de outras tantas experiências que estão porvir no tema da socialização profissional.

Tanto é assim, que em uma pesquisa desenvolvida com professoras iniciantes na mesma cidade, há 5 anos atrás, feita por Morais (2015) evidenciou que as docentes participantes do estudo não tiveram uma socialização profissional com os mesmos moldes, em se tratando de desenvolver atividades no "Terço da Jornada", o que reflete no contexto atual, relacionando-se ao cumprimento da lei do Piso Salarial Profissional Nacional para os profissionais do magistério público da educação básica (PSPN) nos últimos anos no Brasil, no Maranhão e na cidade de Caxias, onde a presente pesquisaformação foi realizada. Portanto, há uma mudança crucial nas políticas educacionais e nos processos de socialização de professores e professoras no cotidiano das escolas. 
Embora todas as professoras iniciantes, participantes do presente trabalho, tenham passado pela experiência como docentes no desenvolvimento de atividades didáticas e pedagógicas no "Terço da Jornada", foi possível compreender que cada uma teve um modo singular e subjetivo de viver a experiência de ser professora, e de saber lidar com as mudanças, expectativas, desejos e emoções que perpassaram o início da carreira docente e o aprender a ser professora.

$\mathrm{O}$ entrelaçamento entre a construção das narrativas escritas de experiências pedagógicas com as conversas no cotidiano e a participação das professoras iniciantes no processo de reconstrução narrativa com os pesquisadores no processo de pesquisaformação mostraram-se como uma potência criadora e fundamental na construção do conhecimento científico, mas não somente isso, aprendemos outras formas de compreender e interpretar a educação, o ser professora e o produzir conhecimentos coletivamente, mediados pela reflexão, conversação e imersão no cotidiano escolar.

Nas narrativas das experiências pedagógicas, de formação e profissionalização das professoras, portanto, acreditamos emergir outros tantos saberes, reflexões e modos de pensar os processos de socialização profissional com professoras iniciantes no cotidiano escolar, podendo servir como subsídios para pensarmos outras tantas lógicas e modos com que acontecem essa socialização na sociedade contemporânea. Questões essas, fundamentais para compreendermos e criarmos propostas de formação de professores e professoras, políticas públicas na área, e dispositivos potenciais de transformação da realidade em se tratando de menos conflituosa como substanciais para o aprimoramento e melhoria da qualidade da educação e da inserção profissional de futuros professores e professoras que escolhem a docência como vida e profissão.

\section{Notas}

1 Pesquisa financiada pela Coordenação de Aperfeiçoamento de Pessoal de Nível Superior (Capes) e que faz parte da tese de doutorado em educação em desenvolvimento do segundo autor deste artigo, orientado pela primeira autora.

2 Neste texto, utilizamos o termo "professora" no feminino pelo respeito ao gênero, porque foram professoras que fizeram parte desta pesquisa e pelo fato de que a maioria das profissionais que estão no magistério são mulheres.

3 Ajunção de duas ou mais palavras como o termo pesquisaformação e outras utilizadas neste texto, trata-se de uma escolha política, teórico-metodológica e epistemológica que fizemos, buscando dar outras tantas significações que extrapolam o modelo clássico de ciência e produção do conhecimento científico. Assim o fizemos adotando também os princípios dos estudos nos/dos/com os cotidianos, como faz Oliveira (2012).

4 Na acepção dos referidos pesquisadores, as palavras-conceito pesquisa e formação vêm lado a lado ou articuladas por hífen. Inspirados nesta tradição e também dos estudos dos/nos/com os cotidianos, temos usado 
no nosso grupo de pesquisa, sendo a primeira autora deste artigo a coordenadora e o segundo autor um dos integrantes, conforme expresso ao longo do presente texto e justificado na segunda nota, pesquisaformação. Esclarecemos, entretanto, que quando fizermos referência à produção dos autores manteremos o uso do hífen.

5 Lei do Piso Salarial Profissional Nacional para os Profissionais do Magistério Público da Educação Básica (Lei n⿳0 11.738/2008) (BRASIL, 2008) (disponível em: http://www.planalto.gov.br/ccivil_03/_ato20072010/2008/lei/111738.htm). O Parecer no. 9 de 2009, do Conselho Nacional de Educação detalha a organização do trabalho docente, prevendo o Horário de Trabalho Pedagógico Coletivo (HTPC) e Horário de Trabalho Pedagógico em Local de Livre Escolha pelo docente (HTPLE). "O HTPC é o horário destinado ao encontro entre os seus pares da unidade escolar, momentos de formação na escola, movimentos de troca dos docentes, reunião pedagógica; o HTPLE consiste no período em que o docente escolhe atividades fora da instituição escolar que possam ampliar seus conhecimentos” (BRAGANÇA; PEREZ, 2016, p. 1167).

6 A professora Fábia trabalhou por um ano em uma escola da rede privada de ensino, mas nos informou que é completamente diferente a organização do ensino, o perfil dos alunos e as múltiplas questões que envolvem a estrutura, condições de trabalho e o próprio universo cultural das crianças, já que a escola em que atua fica situada em uma região periférica da cidade, e a maioria de seus alunos são oriundos de filhos da classe trabalhadora e com baixo poder aquisitivo e econômico.

\section{Referências}

ABRAHÃO, Maria Helena Menna Barreto. Intencionalidade, reflexividade, experiência e identidade em pesquisa (auto)biográfica: dimensões epistemo-empíricas em narrativas de formação. In: BRAGANÇA, I. F. de S.; ABRRAHÃO, M. H. M. B.; FERREIRA, M. S. (org.). Perspectivas epistêmico-metodológicas da pesquisa (auto)biográfica. Curitiba: CRV, 2016. p. 29-50.

BAKHTIN, Mikhail. Para uma filosofia do ato responsável. Tradução de Valdemir Miotello \& Carlos Alberto Faraco. 3. ed. São Carlos: Pedro \& João Editores, 2017.

BRASIL. Lei no 11.738, de 16 de julho de 2008. Regulamenta a alínea "e" do inciso III do caput do art. 60 do Ato das Disposições Constitucionais Transitórias, para instituir o piso salarial profissional nacional para os profissionais do magistério público da educação básica. Brasília, DF, 2008. Disponível em: http://www.planalto.gov.br/ccivil_03/_ato2007-2010/2008/lei/ 111738.htm. Acesso: 10 jul. 2020.

BRASIL. Lei nº 9.394, de 20 de dezembro de 1996. Brasília, DF, 1996. Disponível em: https:// www.planalto.gov.br/ccivil_03/Leis/L9394.htm. Acesso em 10 jul. 2020.

BENJAMIN, Walter. Magia e técnica, arte e política: ensaios sobre literatura e história da cultura. Tradução de Sérgio Paulo Rouanet; prefácio de Jeanne Marie Gagnebin. 8. ed. São Paulo: Brasiliense, 2012. p. 213-240.

BRAGANÇA, Inês Ferreira de Souza. Histórias de vida e formação de professores: diálogos entre Brasil e Portugal. Rio de Janeiro: EdUERJ, 2012. Disponível em: https://doi. org/10.7476/9788575114698. Acesso em: 16 jul. 2020.

BRAGANÇA, Inês Ferreira de Souza; PEREZ, Juliana Godói de Miranda. Formação Continuada em Escolas de Tempo Integral: narrativas de professoras. Educação \& Realidade, Porto Alegre, v. 41, n. 4, p. 1161-1182, out./dez. 2016. Disponível em: https://www.scielo.br/pdf/edreal/ v41n4/2175-6236-edreal-41-04-01161.pdf. Acesso em: 27 jul. 2020. 
DUBAR, Claude. A construção de si pela atividade de trabalho: a socialização profissional. Tradução Fernanda Machado. Cadernos de Pesquisa, v. 42, n. 146, p. 351-367, maio/ago. 2012. Disponível em: https://www.scielo.br/pdf/cp/v42n146/03.pdf. Acesso: 07 jul. 2020.

ESTRELA, Maria Teresa. Profissão docente: dimensões afectivas e éticas. Porto: Areal Editores, 2010.

GOODSON, I. F. Currículo, narrativa pessoal e futuro social. Tradução de Henrique Carvalho Calado; revisão da tradução: Maria Inês Petrucci-Rosa e José Pereira de Queiroz. Campinas, SP: Editora da Unicamp, 2019.

HUBERMAN, Michäel. O ciclo de vida profissional dos professores. In: NÓVOA, António (org.). Vidas de professores. 2. ed. Porto: Porto Editora, 2000. p. 31-46.

ILHA, Franciele Roos da Silva; HYPOLITO, Álvaro Moreira. O trabalho docente no início da carreira e sua contribuição para o desenvolvimento profissional do professor. Práxis Educacional, Vitória da Conquista, v. 10, n. 17, p. 99-114, jul./dez. 2014. Disponível em: http://periodicos2.uesb.br/index.php/praxis/article/view/781/661. Acesso: 09 jul. 2020.

JOSSO, Marie-Christine. Experiências de vida e formação. Tradução de José Cláudio, Júlia Ferreira; revisão de Maria da Conceição Passeggi, Marie-Christine Josso. 2. ed. rev. e ampl. Natal, RN: EDUFRN; São Paulo: Paulus, 2010.

LARROSA, Jorge. Experiência e alteridade em educação. Revista Reflexão e Ação, Santa Cruz do Sul, v. 19, n. 2, p. 04-27, jul./dez. 2011. Disponível em: https://online.unisc.br/seer/index.php/ reflex/article/view/2444. Acesso em: 10 jul. 2020.

MARCELO GARCIA, Carlos. Formação de professores: para uma mudança educativa. Porto: Porto Editora, 1999.

MORAIS, Joelson de Sousa. A prática pedagógica no cotidiano de professoras iniciantes: tramas e desafios do aprender e ensinar. 175 f. Dissertação (Mestrado em Educação) - Centro de Educação, Universidade Federal do Rio Grande do Norte, Natal, 2015. Disponível em: https:// repositorio.ufrn.br/jspui/bitstream/123456789/20460/1/JoelsonDeSousaMorais_DISSERT.pdf. Acesso em: 08 jul. 2020.

MOTTA, Thais da Costa; BRAGANÇA, Inês Ferreira de Souza. Pesquisaformação: uma opção teórico-metodológica de abordagem narrativa (auto)biográfica. Artes de dizerfazerdizer os saberes da experiência. Revista Brasileira de Pesquisa (Auto)Biográfica, Salvador, v. 04, n. 12, p. 1034-1049, set./dez. 2019. Disponível em: https://www.revistas.uneb.br/index.php/rbpab/article/ view/6191. Acesso em: 11 jul. 2020.

OLIVEIRA, Inês Barbosa de. O currículo como criação cotidiana. Petrópolis, RJ: DP et alii; Rio de Janeiro: Faperj, 2012.

RIBEIRO, Tiago; SOUZA, Rafael de; SAMPAIO, Carmen Sanches. É possível a conversa como metodologia de pesquisa? In: RIBEIRO, T.; SOUZA, R. de; SAMPAIO, C. S. (org.). Conversa como metodologia de pesquisa: por que não? Rio de Janeiro: Ayvu, 2018. p. 163-180.

RICOEUR, Paul. Tempo e narrativa. Tradução de Claudia Berliner. Revisão da tradução de Márcia Valéria Martinez de Aguiar. São Paulo: Editora WMF Martins Fontes, 2010. 